\title{
Seroreactivity to Q Fever Among Slaughterhouse Workers in South Korea
}

\author{
Hyuk Chu' ${ }^{1 *}$, Seok-Ju Yoo ${ }^{2 *}$, Kyu-Jam Hwang ${ }^{1}$, Hyun-Sul Lim² ${ }^{2}$ Kwan Lee ${ }^{2}$, Mi-Yeoun Park ${ }^{3}$ \\ ${ }^{1}$ Center for Infectious Disease, Korea National Institute of Health, Korea Centers for Disease Control and Prevention, Cheongju; ${ }^{2}$ Department of \\ Preventive Medicine, Dongguk University College of Medicine, Gyeongju; ${ }^{3}$ Center for Immunology and Pathology, Korea National Institute of Health, \\ Korea Centers for Disease Control and Prevention, Cheongju, Korea
}

Objectives: $\mathrm{Q}$ fever is a zoonotic disease that occurs worldwide; however, little is known about its prevalence in South Korea. We attempted to determine the prevalence of $Q$ fever seroreactivity among Korean slaughterhouse workers and the risk factors for seroreactivity according to the type of work.

Methods: The study was conducted among 1503 workers at a total of 73 slaughterhouses and 62 residual-product disposal plants. During the study period, sites were visited and surveys were administered to employees involved in slaughterhouse work, and serological tests were performed on blood samples by indirect immunofluorescence assays. Serological samples were grouped by job classification into those of slaughter workers, residual-product handlers, inspectors and inspection assistants, and grading testers and testing assistants. Employee risk factors were analyzed according to the type of work.

Results: Out of 1481 study subjects who provided a blood sample, 151 (10.2\%) showed reactive antibodies. When these results were analyzed in accordance with the type of work, the result of slaughter workers (11.3\%) was similar to the result of residual-product handlers (11.4\%), and the result of inspectors and assistants (5.3\%) was similar to the result of grading testers and assistants (5.4\%). Among those who answered in the affirmative to the survey question, "Has there been frequent contact between cattle blood and your mouth while working?" the proportions were 13.4 and 4.6\%, respectively, and this was identified as a risk factor that significantly varied between job categories among slaughterhouse workers.

Conclusions: This study found a $\mathrm{Q}$ fever seroreactivity rate of $10.2 \%$ for slaughterhouse workers, who are known to be a high-risk population. Contact with cattle blood around the mouth while working was the differential risk factor between job categories among slaughterhouse workers.

Key words: Q fever, Coxiella burnetii, Risk factors, Slaughterhouses, Korea

Received: February 6, 2017 Accepted: April 10, 2017

Corresponding author: Mi-Yeoun Park, PhD

187 Osongsaengmyeong 2-ro, Heungdeok-gu, Cheongju 28159, Korea

Tel: +82-43-719-8520, Fax: +82-43-719-8559

E-mail: miyeoun@korea.kr

*Chu \& Yoo have contributed equally to this work as joint first authors.

This is an Open Access article distributed under the terms of the Creative Commons Attribution Non-Commercial License (http://creativecommons.org/licenses/bync/4.0/) which permits unrestricted non-commercial use, distribution, and reproduction in any medium, provided the original work is properly cited.

\section{INTRODUCTION}

Coxiella burnetii is an obligate intracellular bacterium known to be the etiologic agent of $\mathrm{Q}$ fever, a zoonosis in wild and domestic animals with worldwide prevalence [1,2]. Q fever may appear either in an acute form as a febrile flu-like illness with pneumonia, hepatitis and neurologic abnormalities ranging from headache to meningoencephalitis, or in a chronic form as endocarditis, hepatitis, or chronic fatigue syndrome [3,4]. Human infection can result from inhalation of contaminated 
aerosols or ingestion of nonpasteurized milk from infected animals, such as cattle, goats, and sheep [5,6]. Person-to-person transmission is rare, but has been reported to result through sexual contact and aerosol transmission [7].

Previous research has documented the seroprevalence of $\mathrm{Q}$ fever to be 4 to $20 \%$ for cattle, 9 to $57 \%$ for sheep, and 2.5 to $13 \%$ for goats [8]. However, in the case of humans, the seropositive rate of $\mathrm{Q}$ fever has been shown to be significantly different between healthy males and high-risk groups. Macellaro et al. [9] reported that $\mathrm{Q}$ fever seroprevalence in healthy persons was 5 to $17 \%$, but in the case of sheep farmers, it was as high as 24 to $30 \%$, and Monno et al. [10] reported a rate of $13.6 \%$ for a control group, whereas $84 \%$ of animal breeding workers showed a $\mathrm{Q}$ fever seropositive reaction. In addition, Whitney et al. [11] reported a seroprevalence of $22.2 \%$ among veterinarians, and according to Wilson et al. [12], slaughterhouse workers showed a very high rate of seropositivity, at $41.9 \%$.

Little is known about the prevalence and risk factors of $\mathrm{Q}$ fever in South Korea (hereafter Korea). We identified confirmed diagnoses of $\mathrm{Q}$ fever in Korea by checking the National Notifiable Infectious Disease database for cases recorded starting in 2006. Diagnoses of $Q$ fever were reported by Korean hospitals for 72 patients from 2006 through 2011 [13]. In this study, we concentrated on high-risk groups for $\mathrm{Q}$ fever, such as slaughterhouse workers, livestock infection prevention officials, livestock farmers, and researchers, who have many opportunities for contact and exposure with animals.

The aim of this study was to determine the seroreactivity and risk factors of $\mathrm{Q}$ fever among slaughterhouse workers as a high-risk group for $\mathrm{Q}$ fever in Korea, in order to develop customized prevention strategies.

\section{METHODS}

\section{Study Population}

A total of 1503 persons who were employed in relation to slaughterhouse work and who were working at a total of 73 slaughterhouses and 62 residual-products disposal plants in November 2007 were included in this study. Among these subjects, 1481 persons (98.5\%) provided a blood sample for $\mathrm{Q}$ fever antibody tests.

\section{Research Methods}

\section{Site visits and survey}

The structure of the slaughterhouse, the slaughter process, and work characteristics of each slaughterhouse worker were identified through a review of the literature and prior visits to slaughterhouses. Based on this information, a questionnaire was developed to target slaughter workers, residual-product handlers, inspectors and inspection assistants, and grading testers and testing assistants. The questionnaire included questions on the general characteristics of each worker and work-related risk factors, as well as the use of personal protective equipment.

\section{Serological tests}

A 10-mL blood sample of venous blood was taken from each person, and the serum was separated using a portable centrifuge on the spot. The separated serum was shipped in a sealed icebox to a central processing facility and the levels of antibodies against $Q$ fever were measured. We used an indirect immunofluorescence assay (IFA), the standard method of serological diagnosis for $\mathrm{Q}$ fever, in order to detect phase II C. burnetii antibody immunoglobin $\mathrm{G}(\mathrm{lgG})$ and anti-C. burnetii antibody immunoglobin M (IgM) [14]. Positive phase II lgG or IgM antibody values at a dilution of 1:16 or more were classified as seroreactive results. All study participants provided informed consent, and the study design was approved by the appropriate ethics review board (Gyeongyak Article no. 07-80).

\section{Statistical Analysis}

Statistical analysis was performed using SPSS version 17.0 (SPSS Inc., Chicago, IL, USA). The difference by sex in Q fever seroreactivity was analyzed using the Fisher exact test, and the differences by age group and work experience were analyzed using the chi-square test for trend. The significance level was considered to be $p<0.05$.

\section{RESULTS}

\section{General Characteristics of Slaughterhouse Workers}

From October 2007 through April 2008, we enrolled 1530 persons who worked in slaughterhouse and residual-product processing centers in all parts of Korea. Among them, 49 individuals were excluded because they responded to the survey but did not provide a blood sample; 1481 workers were included in the final analysis.

The 1481 participants were classified by type of work and divided into groups of 848 slaughter workers (57.3\%), 351 residual-product handlers (23.7\%), 190 inspectors and inspection 
assistants (12.8\%), and 92 grading testers and testing assistants. A total of 1203 participants (81.2\%) were male and 278 participants (18.8\%) were female. By age, participants were divided into groups of 113 participants $(20.0 \%)<30$ years of age, 296 participants (20.0\%) 30-39 years of age, 474 participants (32.0\%) 40-49 years of age, 450 participants (30.4\%) 50 59 years of age, and 148 participants $(10.0 \%) \geq 60$ years of age. The period for which they had been working in their present occupations ranged from a minimum of 1 year to a maximum of 46 years, and the average period was $8.7 \pm 8.3$ years.

\section{Serological results by job category}

Overall, 151 participants (10.2\%) were found to be seroreactive for C. burnetii. The phase II IgG antibody titer cutoffs ranged from 1:16 to 1:2048. The distribution of the 151 seroreactive participants by titer cutoff was, in order of concentration, $41(27.2 \%)$ at 1:16, $53(35.1 \%)$ at 1:32, $25(16.6 \%)$ at 1:64, $23(15.2 \%)$ at $1: 128,4(2.6 \%)$ at $1: 256$, and $5(3.3 \%)$ at over $1: 256$. By occupational group, 96 of 848 slaughter workers (11.3\%), 40 of 351 residual-product handlers (11.4\%), 10 of 190 inspectors and assistants (5.3\%), and 5 of 92 grading testers and assistants (5.4\%) were seroreactive for $\mathrm{Q}$ fever. The slaughter workers and residual-product handlers, who were more directly exposed to cattle blood and residual-products, were combined into 1 occupation group, labeled job category $\mathrm{I}$, and the inspectors and inspection assistants as well as grading testers and testing assistants, who were less exposed to blood and residual-products, were combined into another occupation group, job category II. The seroreactivity rate showed a significant difference between job categories, with 136 of 1199 workers (11.3\%) for job category I and 15 of 282 workers (5.3\%) for job category II (Table 1).

\section{Serological Results by Sex and Age}

Comparing serological results by sex, 131 of 1203 male participants (10.9\%) and 20 of 278 female participants (7.2\%) showed seroreactivity to $Q$ fever. The difference in these results was not statistically significant. Comparing serological results by age, Q fever seroreactivity was found for 9 of 113 participants (8.0\%) $<30$ years of age, 26 of 296 participants (8.8\%) $30-39$ years of age, 42 of 474 participants ( $8.9 \%) 40-49$ years of age, 54 of 450 participants (12.0\%) 50-59 years of age, and 20 of 148 participants (13.5\%) $\geq 60$ years of age. Seroprevalence showed a tendency to increase significantly with age (Table 2 ).

Table 1. Seroreactivity by job category ${ }^{1}$ and distribution of antibody values

\begin{tabular}{|c|c|c|c|c|c|c|c|c|}
\hline \multirow{2}{*}{ Category } & \multirow{2}{*}{$\begin{array}{l}\text { Seroreactive/ } \\
\text { tested indi- } \\
\text { viduals (n) }\end{array}$} & \multirow{2}{*}{$\begin{array}{l}\text { Seroreactive } \\
\text { rate }(\%)^{* *}\end{array}$} & \multicolumn{6}{|c|}{ Phase Il titer of seroreactive cases (IgG or $\lg M)$} \\
\hline & & & 1:16 & $1: 32$ & 1:64 & 1:128 & 1:256 & $1: 256<$ \\
\hline Slaughter workers & $96 / 848$ & 11.3 & 29 & 33 & 18 & 13 & 1 & 2 \\
\hline Residual-product handlers & $40 / 351$ & 11.4 & 9 & 13 & 6 & 7 & 2 & 3 \\
\hline Inspectors and assistants & $10 / 190$ & 5.3 & 2 & 4 & 1 & 2 & 1 & 0 \\
\hline Grading testers and assistants & $5 / 92$ & 5.4 & 1 & 3 & 0 & 1 & 0 & 0 \\
\hline Total & $151 / 1481$ & 10.2 & 41 & 53 & 25 & 23 & 4 & 5 \\
\hline
\end{tabular}

IgG, immunoglobin G; IgM, immunoglobin $\mathrm{M}$.

'Job category I: slaughter workers, residual-product handlers; job category II: inspectors and inspection assistants, grading testers and testing assistants.

${ }^{* *} p<0.01$ by the chi-square test between job categories I and II.

Table 2. Q fever seroreactivity according to age and sex among slaughterhouse workers

\begin{tabular}{|c|c|c|c|c|c|c|c|c|c|}
\hline \multirow[b]{2}{*}{ Age (y) } & \multicolumn{3}{|c|}{ Male } & \multicolumn{3}{|c|}{ Female } & \multicolumn{3}{|c|}{ Total } \\
\hline & $\begin{array}{c}\text { No. of } \\
\text { examinees }\end{array}$ & $\begin{array}{c}\text { Seroreactive } \\
\text { results }(\mathrm{n})\end{array}$ & $\begin{array}{l}\text { Seroreactive } \\
\text { rate }(\%)\end{array}$ & $\begin{array}{c}\text { No. of } \\
\text { examinees }\end{array}$ & $\begin{array}{c}\text { Seroreactive } \\
\text { results (n) }\end{array}$ & $\begin{array}{l}\text { Seroreactive } \\
\text { rate }(\%)\end{array}$ & $\begin{array}{c}\text { No. of } \\
\text { examinees }\end{array}$ & $\begin{array}{c}\text { Seroreactive } \\
\text { results }(\mathbf{n})\end{array}$ & $\begin{array}{c}\text { Seroreactive } \\
\text { rate }(\%)^{*}\end{array}$ \\
\hline$<30$ & 85 & 7 & 8.2 & 28 & 2 & 7.1 & 113 & 9 & 8.0 \\
\hline $30-39$ & 261 & 23 & 8.8 & 35 & 3 & 8.6 & 296 & 26 & 8.8 \\
\hline $40-49$ & 403 & 38 & 9.4 & 71 & 4 & 5.6 & 474 & 42 & 8.9 \\
\hline $50-59$ & 335 & 46 & 13.7 & 115 & 8 & 7.0 & 450 & 54 & 12.0 \\
\hline$\geq 60$ & 119 & 17 & 14.3 & 29 & 3 & 10.3 & 148 & 20 & 13.5 \\
\hline Total & 1203 & 131 & $10.9^{\dagger}$ & 278 & 20 & $7.2^{\dagger}$ & 1481 & 151 & 10.2 \\
\hline
\end{tabular}

${ }^{*} p<0.05$ by the chi-square for trend among age groups

${ }^{\dagger} p<0.1$ by the chi-square test between male and female participants. 


\section{Serological results by duration of work}

Comparing the seroreactivity rate by duration of work, 711 out of 1160 workers (excluding non-respondents) had $<10$ years of experience, with 64 of 711 (9.0\%) showing seroreactivity. There were 299 workers with 10-19 years of work experience, with 31 of 299 (10.4\%) showing seroreactivity, while 150 workers had $\geq 20$ years of work experience, with 18 of 150 (12.0\%) showing seroreactivity. Therefore, the seroprevalence increased with greater duration of work experience, but these differences were not significant (Table 3).

\section{Risk factor analysis between job categories I and II among slaughterhouse workers}

An analysis of risk factors according to the type of work in the two groups showed significant differences in the seroreactivity rate, with $13.4 \%$ of those in job category I (including slaughter workers and residual-product handlers) responding to the question "Are you splashed with cattle blood around the mouth more than once a week?" in the affirmative. This was significantly higher than the affirmative response rate of those in job category II (including inspectors, grading testers, and assistants), at $4.6 \%(p<0.001)$, other factors did not show

Table 3. Q fever seroreactivity according to duration of work experience among slaughterhouse workers

\begin{tabular}{lccc}
\hline & $\begin{array}{c}\text { No. of } \\
\text { examinees }\end{array}$ & $\begin{array}{c}\text { Seroreactive } \\
\text { results (n) }\end{array}$ & $\begin{array}{c}\text { Seroreactivity } \\
(\%)\end{array}$ \\
\hline $\begin{array}{l}\text { Duration of work }(y)^{1,2} \\
\geq 20\end{array}$ & 150 & 18 & 12.0 \\
$10-19$ & 299 & 31 & 10.4 \\
$<10$ & 711 & 64 & 9.0 \\
\hline
\end{tabular}

'Subjects for whom this variable was unknown were excluded.

${ }^{2} p=0.23$ by the chi-square test for trend among categories of duration of work. significant differences. Of the two groups, 24.4 and $26.2 \%$ in job category I and job category II, respectively, answered in the affirmative to the question "Are you splashed with cattle blood around the body?" and 21.4 and $17.4 \%$, respectively, answered in the affirmative to the question "Are you splashed with cattle secretions around the body?" (Table 4).

\section{DISCUSSION}

Various reports have been published on $\mathrm{Q}$ fever, which is a communicable disease between animals and humans, but $\mathrm{Q}$ fever has rarely been studied in Korea. Reports on Q fever seroprevalence in the medicine and veterinary medicine fields in Korea have been published by Kim et al. [15] and Kwak et al. [16]. However, no research in Korea has focused on Q fever among slaughterhouse workers in all parts of the country. The serological diagnostic criteria for $\mathrm{Q}$ fever vary according to the regional situation and depend on the research methodology $[3,17]$. Thus, it is difficult to compare research findings. In this study, we suggest the identification of a $Q$ fever seroreactive result for positive phase II lgG or IgM antibody results at a dilution of 1:16 or more. Using this criterion, the seroprevalence in the entire sample population of slaughterhouse workers was $10.2 \%$. In particular, the seroreactivity rate for slaughter workers and residual product handlers (job category I) was $11.3 \%$ (136 of 1199), and the seroreactivity rate for inspectors and grading testers (job category II) was 5.3\% (15 of 282). Thus, a difference could be identified between jobs in which there was direct contact with livestock and jobs in which there was not. This was considered to be a result of differences in the opportunities for contact with the blood or byproducts of livestock. Foreign studies have likewise found higher rates of $Q$ fever se-

Table 4. Comparison of work-related risk factors between job categoriesy I and II about work-related risk factor

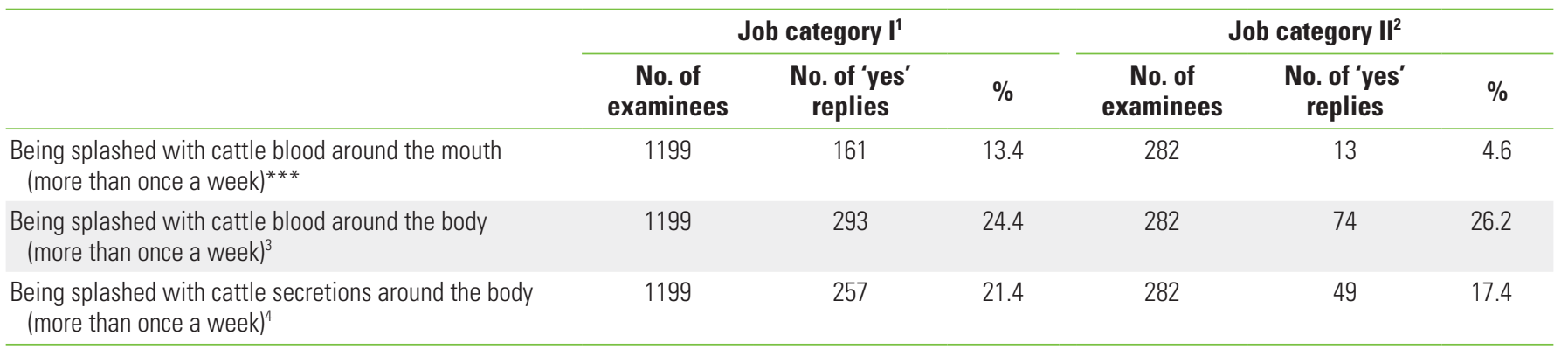

1Job category l: slaughter workers, residual product handlers; job category.

${ }^{2} J o b$ category II: inspectors and inspection assistants, grading testers and testing assistants.

${ }^{3} p=0.53$ by the chi-square test between job categoriesy I and II.

${ }^{4} p=0.13$ by the chi-square test between job categoriesy I and II.

${ }^{* * *} p<0.001$ by the chi-square test between job categoriesy I and II. 
ropositivity among slaughterhouse workers who come into direct contact with livestock than among those who do not.

The Centers for Disease Control of the US suggest that the interpretation of serological results for possible $Q$ fever infection must include differential reactivity to $C$. burnetii antigens. The most commonly means of confirming the diagnosis of acute $\mathrm{Q}$ fever is by the demonstration of a 4-fold rise in phase II IgG by IFA between serum samples from the acute and convalescent phases, taken 3-6 weeks apart. Various values are used by individual laboratories to categorize patients as seropositive or seronegative [18]. In this study, the distinction between acute and convalescent symptoms was difficult to determine, because individuals with symptoms of $\mathrm{Q}$ fever likely did not seek medical care at hospitals, and the identification of symptoms was not exact because the investigation was performed over a period of three months. Insufficient evidence was available to make $\mathrm{Q}$ fever diagnoses by serum assessments in Korea at the time of this survey. Thus, this study focused on $\mathrm{Q}$ fever seroreactive status in order to relate seroanalytical results to the characteristics of slaughterhouse workers. In spite of these limitations, this study is the first survey to identify potential rates of $Q$ fever infection among slaughterhouse workers from all parts of Korea, including island regions. Further epidemiological investigation of $\mathrm{Q}$ fever among highrisk groups is necessary so that customized prevention strategies can be developed. In addition, we hope that these results regarding $\mathrm{Q}$ fever seroreactive status can be used as a basis to develop standard diagnostic criteria for Q fever in Korea.

\section{ACKNOWLEDGEMENTS}

This work was supported by a grant (2007-E00117-00) from the Korea Centers for Disease Control and Prevention.

\section{CONFLICT OF INTEREST}

The authors have no conflicts of interest associated with the material presented in this paper.

\section{ORCID}

Hyuk Chu http://orcid.org/0000-0002-7044-2942

Seok-Ju Yoo https://orcid.org/0000-0001-9764-8097

Hyun-Sul Lim http://orcid.org/0000-0001-9972-2561

Kwan Lee http://orcid.org/0000-0003-2554-4170
Mi Yeoun Park https://orcid.org/0000-0002-5356-8666

\section{REFERENCES}

1. Vogel JP. Turning a tiger into a house cat: using Legionella pneumophila to study Coxiella burnetii. Trends Microbiol 2004;12(3):103-105.

2. Hilbink F, Penrose M, Kovacova E, Kazar J. Q fever is absent from New Zealand. Int J Epidemiol 1993;22(5):945-949.

3. Maurin M, Raoult D. Q fever. Clin Microbiol Rev 1999;12(4): 518-553.

4. Angelakis E, Raoult D. Emergence of Q fever. Iran J Public Health 2011;40(3):1-18.

5. McQuiston JH, Childs JE. Q fever in humans and animals in the United States. Vector Borne Zoonotic Dis 2002;2(3):179-191.

6. Raoult D, Marrie T, Mege J. Natural history and pathophysiology of Q fever. Lancet Infect Dis 2005;5(4):219-226.

7. Raoult D. Q fever: still a query after all these years. J Med Microbiol 1996;44(2):77-78.

8. Arricau-Bouvery N, Rodolakis A. Is Q fever an emerging or reemerging zoonosis? Vet Res 2005;36(3):327-349.

9. Macellaro A, Akesson A, Norlander L. A survey of Q-fever in Sweden. Eur J Epidemiol 1993;9(2):213-216.

10. Monno R, Fumarola L, Trerotoli P, Cavone D, Giannelli G, Rizzo $C$, et al. Seroprevalence of $Q$ fever, brucellosis and leptospirosis in farmers and agricultural workers in Bari, Southern Italy. Ann Agric Environ Med 2009;16(2):205-209.

11. Whitney EA, Massung RF, Candee AJ, Ailes EC, Myers LM, Patterson $\mathrm{NE}$, et al. Seroepidemiologic and occupational risk survey for Coxiella burnetii antibodies among US veterinarians. Clin Infect Dis 2009;48(5):550-557.

12. Wilson LE, Couper S, Prempeh H, Young D, Pollock KG, Stewart WC, et al. Investigation of a $Q$ fever outbreak in a Scottish colocated slaughterhouse and cutting plant. Zoonoses Public Health 2010;57(7-8):493-498.

13. Korea Centers for Disease Control and Prevention. Statistics about Q fever from 2006-2014 [cited 2017 Apr 29]. Available from: https://is.cdc.go.kr/dstat/jsp/stat/stat0001.jsp (Korean).

14. Dupont HT, Thirion X, Raoult D. Q fever serology: cutoff determination for microimmunofluorescence. Clin Diagn Lab Immunol 1994;1(2):189-196.

15. Kim WJ, Hahn TW, Kim DY, Lee MG, Jung KS, Ogawa M, et al. Seroprevalence of Coxiella burnetii infection in dairy cattle and non-symptomatic people for routine health screening in Korea. J Korean Med Sci 2006;21(5):823-826. 
16. Kwak W, Chu H, Hwang S, Park JH, Hwang KJ, Gwack J, et al. Epidemiological characteristics of serologically confirmed $\mathrm{Q}$ fever cases in South Korea, 2006-2011. Osong Public Health Res Perspect 2013;4(1):34-38.

17. Setiyono A, Ogawa M, Cai Y, Shiga S, Kishimoto T, Kurane I. New criteria for immunofluorescence assay for $Q$ fever diag- nosis in Japan. J Clin Microbiol 2005;43(11):5555-5559.

18. Anderson A, Bijlmer H, Fournier PE, Graves S, Hartzell J, Kersh GJ, et al. Diagnosis and management of $Q$ fever--United States, 2013: recommendations from CDC and the Q Fever Working Group. MMWR Recomm Rep 2013;62(RR-03):1-30. 